\title{
Open-field social behavior in rats as a function of septal lesions in infancy and group versus isolated rearing conditions
}

\author{
DAVID A. JOHNSON, MARTHA SPIKER, and KIM CARLSON \\ Ohio University, Athens, Ohio
}

\begin{abstract}
Normal rat pups and pups with septal lesions produced at 7 days of age were reared after weaning under group and isolated housing conditions. Contact time between pairs of animals in the open field was observed at 90-110 days of age. Gregariousness was increased by both septal lesion treatment and isolated rearing conditions. The housing condition variable accounted for a greater proportion of treatment variance than did the lesion variable. These results stress the importance of housing conditions as a confounding variable in studies of recovery from infant brain damage.
\end{abstract}

Jonason and Enloe (1971) reported a dramatic increase in open-field gregariousness of the rat following lesions of the septal forebrain. Johnson's (1972) studies indicated that the enhancement of gregariousness effect can be observed regardless of the age at the time the lesion was produced. Meyer, Ruth, and Lavond (1978) demonstrated that the impact of septal lesions on social contact in the rat is potent and lasting.

A body of evidence has been produced primarily by Latané and his colleagues (Latané, Nesbitt, Ekman, \& Roden, 1972) that isolated vs. social housing conditions is also a potent variable in the openfield gregariousness of rats. The Latané studies indicate that adult rats housed in isolation are more gregarious in the open field than are animals reared in group cages.

In the Johnson (1972) experiment, following septal lesions, animals were housed individually from 45 days of age until open-field observations on adult animals were completed. It is possible that the isolated housing conditions might have confounded the data relevant to the lesion variable in that study. In order to more clearly view potential recovery of function following septal lesions, we need more information on how septal lesions in infancy and housing conditions during development interact.

The current study was designed to evaluate the interaction of housing conditions during development and septal lesions in infancy.

\section{METHOD}

\section{Design, Subjects, and Housing}

Each litter was culled to eight male pups at 5 days of age. At 7 days of age, 48 pairs of animals were assigned to four groups (12

The authors' mailing address is: Department of Psychology, Ohio University, Athens, Ohio 45701. pairs in each group) according to lesion and housing treatments: normal group (NG), normal isolate (NI), septal group (SG), and septal isolate (SI). All animals were male Long-Evans hooded rats bred in our laboratory. Two animals from each litter were assigned to each group. The dam and each litter were housed in a $60 \times 30 \times$ $20 \mathrm{~cm}$ stainless steel group cage from birth until 30 days of age. At 30 days of age, all animals were separated from their dams. Animals in Groups SI and NI were isolated with one animal per standard $28 \times 20 \times 20 \mathrm{~cm}$ stainless steel rack cage. After the removal of pups to be isolated, the three or four animals in each litter that remained were placed by litter in the same standard rack cage. Thus, in most cases, two pups from Group NG and two from Group SC were housed together in the standard rack cage until completion of the experiment. There were 10 deaths before age 30 days $(4$ normal pups and 6 septal pups) and 6 deaths after differential housing conditions were established ( 1 in Group NI, 3 in Group SI, 2 in Group SG, and 2 in Group NG). After histology, data from five pairs of septal animals were excluded from analysis because of a significant error in lesion placement in at least one pair member. The final number of pairs per group was: Group NI, 6; Group NG. 6; Group SI, 7; and Group SG, 6. Thus, the analysis of data is based on 25 pairs of animals. For observation in all groups, pairs were formed by taking two animals from different litters such that although animals in Groups SG and NG grew up in the group cages no pair members had ever been exposed to each other until placed in the open field.

\section{Surgery}

At 7 days of age, all animals in Groups SG and SI received septal lesions. The procedure for placing lesions is described extensively in prior articles (Johnson, 1972; Johnson, Poplawski, Lancaster, \& Jackson, 1974). The animals were anesthetized by being placed in a jar containing a cotton sponge saturated with methoxyflurane and being kept there until $1 \mathrm{~min}$ after struggling ceased. For the surgery, the animal was supported by a clay mold that held the pup's head horizontal. A small incision was produced above bregma. An electrode, insulated except for $.5 \mathrm{~mm}$ at the tip, was lowered through a small cut in the cartilaginous skull. The electrode was lowered bilaterally at the following coordinates relative to the intersections of the longitudinal and bregmal sutures; $\mathrm{AP}+.5 \mathrm{~mm}, \mathrm{DV}-4.5 \mathrm{~mm}, \mathrm{~L} \pm .5 \mathrm{~mm}$. A current of $1.5 \mathrm{~mA}$ was passed for $20 \mathrm{sec}$ through the electrode. The circuit was completed by taping the cathode to the pup's tail and hindlimbs, which were coated with electrode cream. Ear-clip markings were used to label the animals by group. Control animals received all aspects of the surgical treatment except the actual lesion placement. All animals 
were returned to their home cages following the surgical procedure. When the last animal in each litter was active, the mother was returned to the cage.

\section{Procedure}

During development, the animals were maintained, as indicated above, under either group or isolated housing conditions. In spite of a few deaths, all group cages contained three to four animals. At 90 days of age, the animals in group cages were marked for easy identification, experimental pairs were chosen (animal No. 1 litter 1 with animal No. 1 litter 2, etc.), and observations were initiated. All behaviors recorded were observed in a Latané open field. Since prior studies (Jonason \& Enloe, 1971) had indicated that contact time and open-field activity were related, the first behavior observed was activity level. Each animal was placed in the open field before any social behavior was observed and total number of squares crossed in a 10-min interval was recorded by trained observers as an index of activity. Activity scores were collected on Day 1 and Day 2 of observation and on the last 2 days of observation.

\section{RESULTS}

\section{Histology}

Septal lesions produced in the brains of infant animals are, in general, more variable than are similar lesions in adult rats. As can be seen in Figure 1, the lesions were large. In most animals there was some damage to the corpus callosum immediately adjacent to the dorsal septum. Data from five pairs of septal animals were excluded from analysis because of a ventral spread of the lesion into hypothalamic tissues. Animals retained in the study had complete septal lesions with only minor intrusions into adjacent caudate, cortical, or hypothalamic tissue. The lesion displayed in Figure 1 was the largest lesion, although all were reasonably comparable. The lesions ended posteriorly in the body of the fornix.

\section{Behavior}

A 2 between ( 2 levels of housing, 2 levels of surgery), 1 within (4 days) analysis of variance indicated that activity level in the open field did not differ significantly between groups or across days during the first 2 or last 2 days of observation. The mean number of open-field squares crossed per day by group were as follows: Group NI, 155; Group NG, 135; Group SI, 168; and Group SG, 147.

Open-field contact data are presented in Figure 2. A 2 between, 1 within analysis of variance was used to analyze the open-field data as above, except that there were 15 days in this analysis. The animals with septal lesions produced in infancy were more gregarious $[F(1,25)=6.53, p<.02]$ than the animals without septal lesions. The animals reared in isolation spent much more time in social contact than did the animals housed in groups during development $[F(1,25)=89.93, p<.001]$. The nonsignificant interaction of lesion $x$ rearing conditions $(F<1.0)$ indicates that the impact of septal lesions was the same

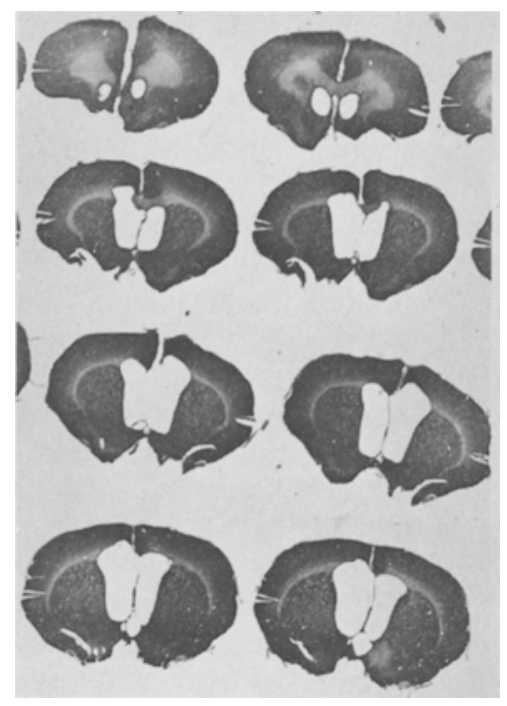

Figure 1. Photomicrograph of sections through the largeat lesion.

across housing conditions. There was a significant increase across days in contact time in all groups $[F(14,350)=12.21, p<.001]$. The animals with septal lesions increased contact time similarly across days regardless of rearing condition, as indicated by the insignificant interaction of lesion $x$ days $[F(14,350)$ $=1.04, p>.40$ ]. On the other hand, the animals from the isolated housing condition, regardless of lesion treatment, increased their levels of social contact more rapidly across days than did the animals from the group housing conditions. This is demonstrated by the significant rearing $x$ days interaction $[F(14,350)$ $=2.64, \mathrm{p}<.001]$. Computation of $\mathrm{W}^{2}$ data confirms what visual inspection of Figure 2 suggests. Sixtyfour percent of the between-group variance is accounted for by the housing variable, whereas $7 \%$ of the between-group variance can be attributed to the effect of lesion vs. normal treatment.

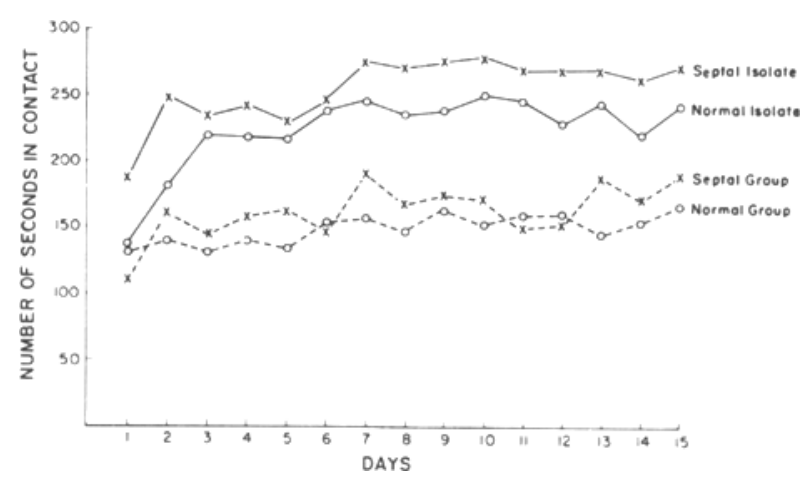

Flgure 2. Open-field contact time across successive days of observation. 


\section{DISCUSSION}

In the current study, both septal lesion and isolated housing conditions resulted in increased social contact in the rat when observed in the open field. We were surprised, however, by the relative saliency of the housing variable. The original report of septal lesions in infant rats (Johnson, 1972) noted the apparent lack of recovery in open-field contact time following both infant septal lesions at 7 days of age and social deprivation from 45 to 120 days of age. In retrospect, it is hard to evaluate the relative contribution of these two conditions to the enhanced gregariousness observed. The current study indicates that the enhanced social gregariousness is not quite so noticeable following septal lesions in infancy if group housing is maintained. Further studies involving social deprivation and infant versus adult septal lesions are needed to clarify the recovery-of-function effect. The current study clearly indicates the need to control social housing conditions during development.

\section{REFERENCES}

Johnson, D. A. (1972). Developmental aspects of recovery of function following septal lesions in the infant rat. Journal of Comparative and Physiological Psychology. 78, 331-348.

Johnson, D. A., Poplawsky, A., Lancaster, J., \& Jackson, R. (1974). Techniques and problems in the stereotaxic placement of subcortical lesions in infant rats. Physiology \& Behavior, 13, 465-470.

Jonason, K. R., \& Enloe, L. J. (1971). Alterations in social behavior following septal lesions and amygdaloid lesions in the rat. Journal of Comparative and Physiological Psychology, 75, 286-301.

Latané, B., Neseitt, P., Eckman, J., \& Rodin, J. (1972). Long and short term social deprivation and sociability in rats. Journal of Comparative and Physiological Psychology, 81, 69-75.

Meyen, D. R., Ruth, R. A., \& Lavond, D. G. (1978). The septal social cohesiveness effect: Its robustness and main determinants. Physiology \& Behavior, 21, 1027-1029.

(Manuscript received January 3, 1983;

revision accepted for publication February 10, 1984.) 